\title{
Electronic Health Lifestyle Coaching Among Diabetes Patients in a Real-Life Municipality Setting: Observational Study
}

Anastasija Komkova ${ }^{1}$, MSc; Carl Joakim Brandt ${ }^{2}$, MD, PhD; Daniel Hansen Pedersen ${ }^{3}$, MSc; Martha Emneus ${ }^{1}$, MSc; Camilla Sorts $\varnothing^{1}, \mathrm{PhD}$

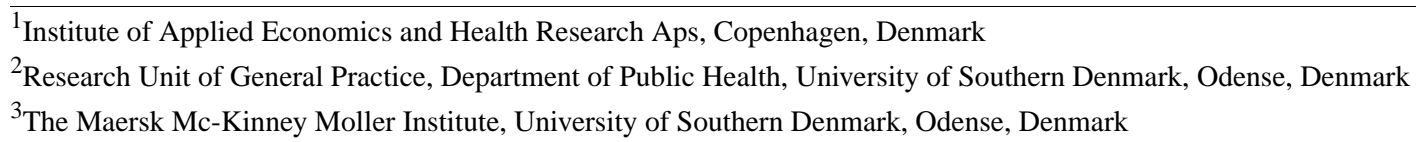

Corresponding Author:

Anastasija Komkova, MSc

Institute of Applied Economics and Health Research Aps

Ewaldsgade 3

Copenhagen, 2200

Denmark

Phone: 4528817307

Email: akom@appliedeconomics.dk

\section{Abstract}

Background: Internet and mobile interventions aiming to promote healthy lifestyle have attracted much attention because of their scalability and accessibility, low costs, privacy and user control, potential for use in real-life settings, as well as opportunities for real-time modifications and interactive advices. A real-life electronic health (eHealth) lifestyle coaching intervention was implemented in 8 Danish municipalities between summer 2016 and summer 2018.

Objective: The aim of this study was to assess the effects associated with the eHealth intervention among diabetes patients in a real-life municipal setting. The eHealth intervention is based on an initial meeting, establishing a strong empathic relationship, followed by digital lifestyle coaching and collaboration supported by a Web-based community among patients.

Methods: We conducted an observational study examining the effect of an eHealth intervention on self-reported weight change among 103 obese diabetes patients in a real-life municipal setting. The patients in the study participated in the eHealth intervention between 3 and 12 months. A weight change was observed at 6, 9, and 12 months. We used regression methods to estimate the impacts of the intervention on weight change.

Results: We found that the eHealth intervention significantly reduced weight among diabetes patients, on average $4.3 \%$ of the initial body mass, which corresponds to $4.8 \mathrm{~kg}$ over a mean period of 7.3 months. Patients who were in intervention for more than 9 months achieved a weight reduction of $6.3 \%$ or $6.8 \mathrm{~kg}$.

Conclusions: This study brings forward evidence of a positive effect of a real-life eHealth lifestyle intervention on diabetes patients' lifestyle in a municipal setting. Future research is needed to show if the effect is sustainable from a long-term perspective.

(JMIR Diabetes 2019;4(1):e12140) doi: 10.2196/12140

\section{KEYWORDS}

eHealth; diabetes mellitus; healthy lifestyles; weight reduction; obesity

\section{Introduction}

\section{Background}

A majority of premature deaths from noncommunicable diseases are preventable by facilitating healthier lifestyles $[1,2]$. Recent systematic reviews conclude that Web-based and mobile digital electronic health (eHealth) solutions can improve lifestyle behaviors [3-8]; however, they also stress that there is a lack of “...available weight loss interventions suitable to the real-world PC setting, with most research and guideline formulation conducted inside academic silos..." [5] as well as there is a "...need for long-term interventions to evaluate sustainability" [4]. The authors have previously found that eHealth lifestyle coaching providing various behavior change techniques (BCTs) such as tailored information, self-monitoring, lifestyle coaching, in-person feedback, reminders, and person-to-person support based on a strong personal relationship led to a significant 
weight loss of $7.0 \mathrm{~kg}$ during a 20-month period [9]. A refinement of this eHealth intervention (LIVA) [10] was implemented in 8 Danish municipalities between summer 2016 and summer 2018 on the basis of a number of qualitative studies [11,12].

Municipalities invest in preventive programs with the ambition of reducing health care professional (HCP) input and time per patient while still enabling tailored and effective care [2,4,13-15]. eHealth lifestyle coaching is markedly more efficient than traditional in-person meetings [16].

In this study, we applied an observational design to investigate the first outcome data on self-reported weight change among diabetes patients participating in an eHealth intervention with municipality HCPs for at least 3 months. We combine these results with literature findings regarding the impact of weight change on diabetes patients' costs in a municipality perspective to estimate the potential savings related to societal costs of diabetes.

The aim of this study was to evaluate data regarding self-reported weight change of eHealth lifestyle coaching among diabetes patients and assess impacts associated with offering the program as tertiary prevention among diabetes patients in Danish municipalities.

\section{Research Design}

This is an observational study examining the effect of an eHealth lifestyle intervention on self-reported weight change among diabetes patients in a real-life municipality setting.

\section{Setting and Study Population}

The eHealth intervention was implemented in an ongoing process in 8 Danish municipalities between summer 2016 and summer 2018. Each municipality offered the eHealth intervention within their own organizational framework with local HCPs such as dieticians, nurses, physiotherapists, and occupational therapists, with wide decision discretion resulting in a heterogeneous program setting.

The study population consisted of 103 diabetes patients obese at baseline, with body mass index $(\mathrm{BMI}) \geq 30$, who (1) had used the eHealth platform at any time point between June 7, 2016, and May 2, 2018, (2) had registered to use the platform because of their diabetes, (3) had at least 90 days and maximum 365 days between their first and the last weight measurement registration, and (4) had no registrations of unrealistic rapid weight change $(>0.5 \mathrm{~kg} /$ day $)$. All data on patients were collected from the intervention database based on patients' own and their HCPs' registrations.

\section{Methods}

\section{Intervention}

An eHealth lifestyle coaching intervention has been developed by applying the experiences from previously developed Web-based eHealth solutions used by approximately 140,000 individuals for more than 15 years on which extensive research has been conducted $[6,11,16,17]$.

The key concepts in the eHealth intervention are listed in Textbox 1, and an overview is given in Figure 1.

The intervention provides various BCT's evidenced to be effective for changing lifestyle such as tailored information, self-monitoring, lifestyle coaching, in-person feedback, reminders, and peer-to-peer support [18]. By establishing a personal relationship initially in a face-to-face meeting, which is then continued digitally through the eHealth intervention, the intervention enables tailored care and sustained patient engagement over time with a minimal of HCP input in the process of successfully changing lifestyle and sustaining this change $[6,9,16]$.

Participants in the intervention were introduced to the eHealth intervention by a municipal HCP during a first face-to-face meeting of approximately $45 \mathrm{~min}$ to $60 \mathrm{~min}$. Together, the participant and the municipal HCP established a relationship and agreed on goals for diet, physical exercise, sleep, and other life areas if relevant. Goal setting is based on the specific, measurable, attainable, relevant, and timely (SMART) model according to a predefined guideline structure, described in Table 1. All advices are based on recommendations from the Danish National Board of Health.

Textbox 1. Key concepts of the electronic health intervention.

1. Establishment of an empathic relationship with a health care professional (HCP) in an initial face-to-face meeting.

2. Integration of main stakeholders (HCPs in the municipalities and the patients' personal profile through smartphone or Web-based), allowing for HCPs to look over the shoulder of the patient.

3. Intuitive design enables ease of use for both the user ( $<1 \mathrm{~min}$ for registration a day) and HCPs (5-10 min per consultation) developed through ongoing extensive and systematic user involvement.

4. Different modes of communication channels allow for active communication at all levels of prerequisites among users, creating peer-to-peer support.

5. The backend control panel, including a content library and communication templates, enables optimizing of tailored quality advices asynchronously and via short message service text messaging and video. 
Figure 1. Overview of the eHealth intervention.

\section{Driving patient outcomes, health care delivery efficiency, and insights via data mining}

\section{The 3 essential platform components}
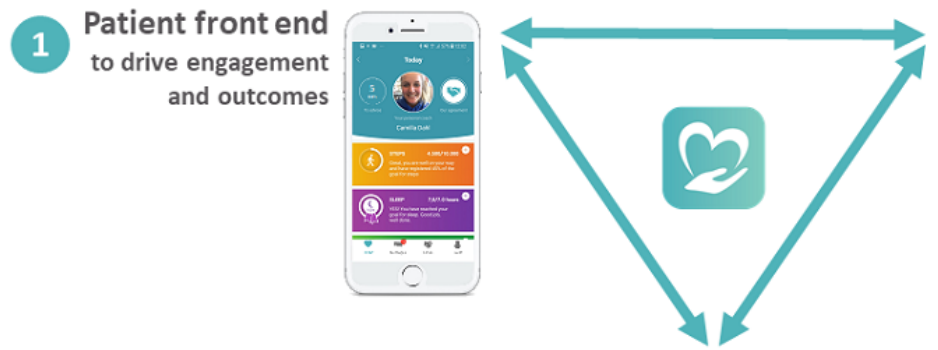

2 Health professional platform

to drive health care delivery efficiency

3

Data mining cockpit

to drive real-world and real-time insights

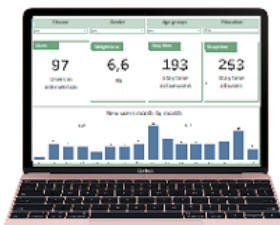

The patients registered their data on a smartphone or logged into a personal profile using the internet (see Figure 2).

The patients filled in a daily record as well as their comments, concerns, and questions to the municipal HCP, who had access to the participant profiles through a control panel. The municipal HCP provided individual asynchronous online consultation according to the patient's needs based on the patient's own registrations. The municipal HCP encouraged and praised goal attainment and sought to maintain the patient motivation. Within the first 3 months, patients were guided by the municipal HCP once every week. In the following 2 months, consultations were provided every second week. After this, guidance took place monthly until 12 months. The following year, the patient proceeded to the retention phase, receiving quarterly consultations described in Figure 3.

\section{Data Analysis}

Outcome data were pooled across municipalities, and average findings were reported. We used a descriptive statistics approach to summarize characteristics of the study population. We reported means and SDs. We estimated weight change among diabetes patients in the periods of up to 6,9 , and 12 months. To examine the intervention impact on weight change, we used ordinary least square regression, including age, gender, and initial BMI as confounders. We investigated the effect of potential explanatory variables: number of messages sent by the patient, number of posts written in the forum, and engagement rate, which is the percentage of weeks where a patient actively uses the app out of the total weeks in the intervention. Applying $t$ test and analysis of variance (ANOVA) tests, we compared weight change between male and female patients as well as across 3 age groups: $<40$ years, $40-59$ years, and $\geq 60$ years. Statistical significance was inferred at a 2 -tailed $P<.05$. All analyses were completed using Stata version 14.1 (Stata, College Station, TX, USA). 
Table 1. Template for intervention description and replication checklist for the electronic health lifestyle intervention.

\begin{tabular}{|c|c|}
\hline TIDieR $^{\mathrm{a}, \mathrm{b}}$ checklist item & Description \\
\hline What? & $\begin{array}{l}\text { The health care professionals (HCPs) received training in setting SMART }{ }^{\mathrm{c}} \text { goals and digital coaching. Patients } \\
\text { receive } 1 \text { or } 2 \text { personal meetings (face-to-face or digital) with the HCP, followed by asynchronous Web-based } \\
\text { consultations based on dialog by means of short message service text message or video. The consultations addressed } \\
\text { the patient's registrations, goal setting, and questions regarding diet, exercise, and lifestyle plan and took chronic } \\
\text { diseases into consideration. The LIVA app is set up with short explanations on different functions and notifications } \\
\text { and reminders to the patients to register and give feedback on the health coaching. The sessions provide the user } \\
\text { with information in relation to their status, specific focus on goals, and recommendations on how to improve their } \\
\text { behaviors. }\end{array}$ \\
\hline
\end{tabular}

eHealth coaching sessions

Goals and inputs

Dietary goals and plans

Physical activity goals and plans

Life goals

Weight-input

Steps-input

Pain, sleep, and mood-input

Smoking-input

Blood glucose, cholesterol, and lung capacity-input

Forum

Who provided?

How?

Where?

When and how much?

Tailoring
Included $\mathrm{BCT}^{\mathrm{d}}$ from $\mathrm{CALO}-\mathrm{RE}^{\mathrm{e}}$ taxonomy (hereafter referred to as $\mathrm{BCT}$ ): provide information on consequences of the behavior in general and to the individual, goal setting: behavior and outcome, action planning, barrier identification or problem solving, set graded tasks, prompt review of behavioral goals, prompt review of outcome goals, prompt rewards contingent on effort or progress toward behavior, prompting generalization of a target behavior, and provide feedback on performance.

The goals and inputs described underneath are available to the patient, who can choose his or her focus area, set specific concrete goals, and keep record of specified behaviors by reporting on them on a daily, weekly, or monthly basis. This allows the user and the HCP to follow progress or setbacks as the numbers and registrations get visualized with graphs and curves. All advices from the HCP follow national guidelines from the Danish National Board of Health.

Dietary goals and plans can be set at many different levels from simple changes aiming at changing 1 meal a day to more complex changes aiming at a completely new diet composition to remedy digestion problems.

Goal setting and recording of type and time for executing any given physical activity. The user receives advice and/or video on activities in a variety of contexts to foster physical activity as a more integrated part of the person's life (BCT: provide instruction on how to perform the behavior, prompting generalization of a target behavior, and relapse prevention or coping planning).

Goals on a healthy, joyful life as the patient sees it, for example, daily life with less stress, stronger social bonds with friends and family, and coping skills for diseases.

Set current weight and goal for a lower or higher weight and register new measurements on a daily, weekly, or monthly basis.

When downloading the app, the user can accept that their information on steps recorded on a smartphone are imported directly, and tailored messages on progress toward a set goal appear simultaneously (BCT: teach to use prompts or cues).

Give daily feedback on pain, sleep, and mood, which can affect the ability to perform a given behavior (BCT: relapse prevention or coping planning).

Set goals to bring down the number of cigarettes smoked on a daily basis, leading to cessation.

Keeping a record of specified measures expected to be influenced by the different behavior changes addressed. In LIVA, this includes blood glucose, cholesterol, and lung capacity. (BCT: prompt self-monitoring of behavioral outcome and provide information on consequences of the behavior in general and to the individual).

Online forum where the users can exchange knowledge, gain social support, and build new relationships; the health coach can add advices to the forum users (BCT: plan social support or social change).

Health professionals with basic training as nurses, physiotherapist, dieticians, and occupational therapists were performing the health coaching.

Individually delivered via the app or Web.

Initial personal meeting in the health centers or digital. Then solely Web-based delivery.

The initial consultations with a health coach is estimated to last approximately 45 to $60 \mathrm{~min}$. The following asynchronous eHealth coaching sessions were carried out once weekly in the first 3 months and then for maintenance every third week for the last 9 months. Hereafter, the patient can receive 2 eHealth coaching sessions and use LIVA as a personal behavioral change tool. (BCT: use of follow up prompts).

Every patient received personal eHealth coaching sessions from their designated health coach. The feedback given was based on the patient's inputs on LIVA.

${ }^{\mathrm{a}}$ TIDieR: template for intervention description and replication.

${ }^{\mathrm{b}}$ On the basis of the study by Hoffmann et al [19].

${ }^{\mathrm{c}}$ SMART: specific, measurable, agreed upon, realistic, and time-based goals.

${ }^{\mathrm{d}} \mathrm{BCT}$ : behavior change technique.

${ }^{\mathrm{e}}$ CALO-RE: Coventry, Aberdeen, and London-Refined taxonomy [20]. 
Figure 2. Patient experience using the eHealth intervention.

The key to long-term outcomes in diverse populations is individual tailor-made interventions,

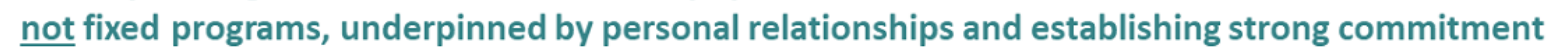
between patient and health coach

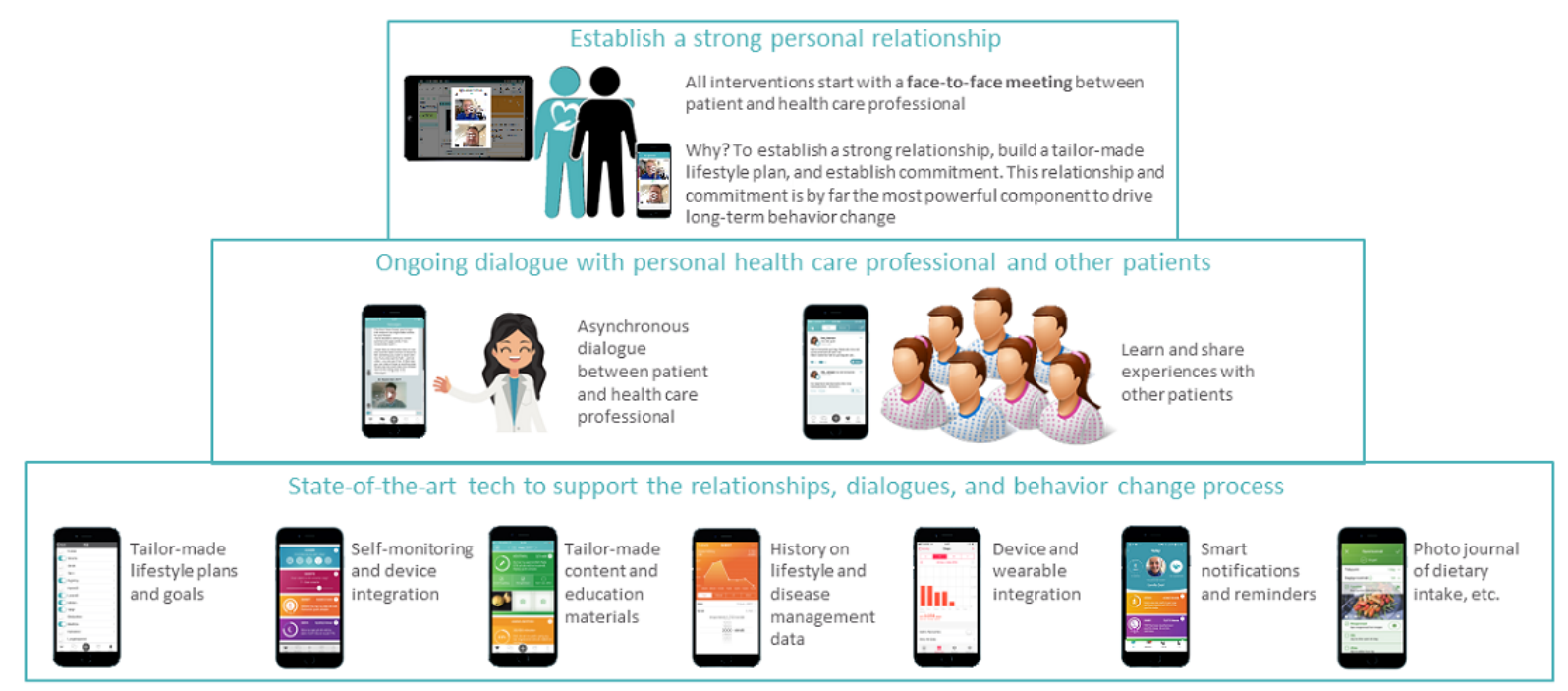

Figure 3. Healthcare professionals experience using the eHealth intervention.

Health care professional view

Maximum engagement with maximum efficiency

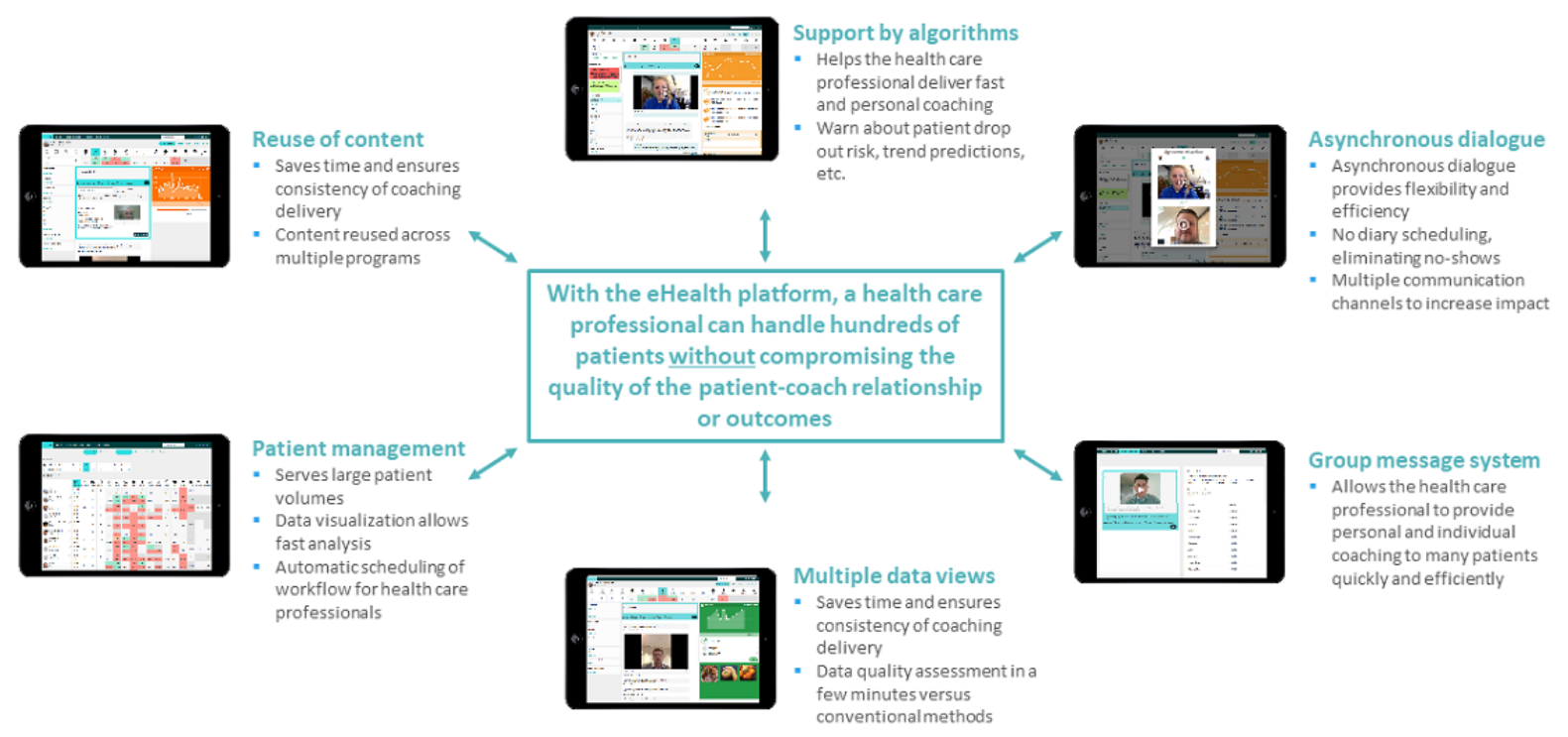

\section{Results}

\section{Patients at Baseline}

On average, diabetes patients who participated in the program for 90 days or longer were obese at baseline, with 57 out of 103 $(55.3 \%)$ being females. The study population has on average been in the intervention for 220 days ( 7.3 months; Table 2).

\section{Observed Weight Change}

Majority of the study population, 88 out of 103 participants (85.4\%), lost weight, whereas 15 patients $(15 / 103,14.6 \%)$ maintained or gained weight (Figure 4).

According to the examined data, on average, individuals with diabetes reduced their weight by $4.78 \mathrm{~kg}$ or $4.3 \%$ of their initial body mass, which corresponds to a 1.58-point change in BMI. Female patients lost $4.22 \%$ of the initial body mass, whereas male patients reduced their weight by $4.41 \%$ (Table 3 ). 
Table 2. Baseline characteristics of the study population.

\begin{tabular}{lc}
\hline Characteristics & Statistics \\
\hline Individuals (n) & 103 \\
Age (years), mean (SD) & $55.6(10.8)$ \\
Female, $\mathrm{n}(\%)$ & $57(55.3)$ \\
Weight $(\mathrm{kg})$, mean (SD) & $106.8(18.8)$ \\
Body mass index $\left(\mathrm{kg} / \mathrm{m}^{2}\right)$, mean (SD) & $36.0(5.2)$ \\
Duration (days), mean (min, max) & $219.9(92,365)$ \\
\hline
\end{tabular}

Figure 4. Observed weight change among the diabetes patients.

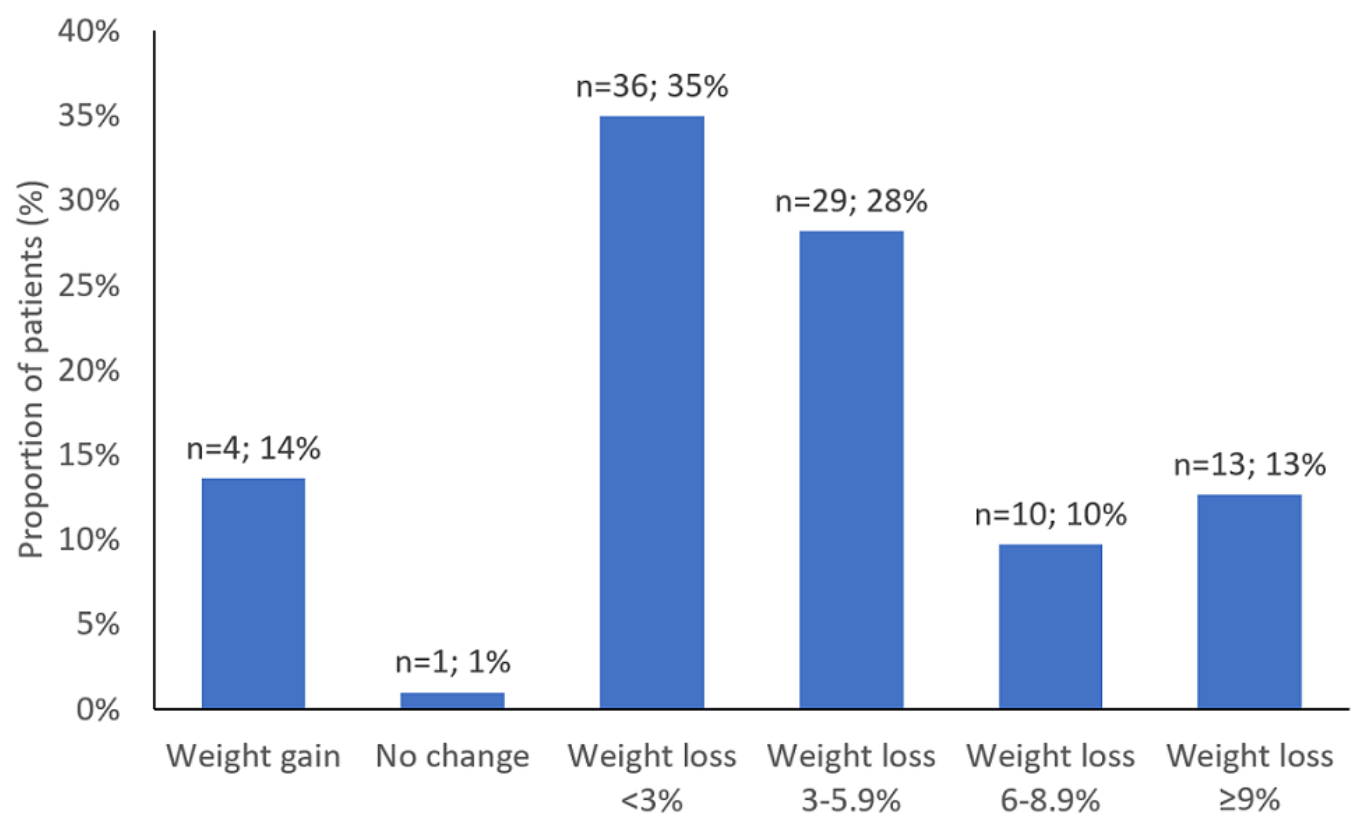

Table 3. Weight change during the intervention according to the observation period (duration).

\begin{tabular}{|c|c|c|c|c|}
\hline Characteristics & Duration (90-365 days) & Duration (90-179 days) & Duration (180-269 days) & Duration (270-365 days) \\
\hline Individuals (n) & 103 & 97 & 54 & 39 \\
\hline Female, n (\%) & $57(55.3)$ & $53(55)$ & $31(57)$ & $21(54)$ \\
\hline Duration (days), mean (min, max) & $219.9(92,365)$ & $148.8(92,179)$ & $240.5(182,269)$ & $330.5(273,365)$ \\
\hline Weight change $(\mathrm{kg})$, mean (SD) & $-4.78(6.67)$ & $-4.31(5.9)$ & $-6.14(7.92)$ & $-6.78(8.1)$ \\
\hline $\begin{array}{l}\text { Weight change ( } \% \text { of initial weight), } \\
\text { mean (SD) }\end{array}$ & $-4.3(5.93)$ & $-3.9(5.34)$ & $-5.56(6.93)$ & $-6.27(7.64)$ \\
\hline Weight change in female & $-4.22(6.83)$ & $-0.91(6.09)$ & $-5.96(8.03)$ & $-6.78(9.12)$ \\
\hline Weight change in male & $-4.41(4.63)$ & $-3.9(4.33)$ & $-5.02(5.23)$ & $-5.68(5.67)$ \\
\hline $\begin{array}{l}\text { Body mass index change }\left(\mathrm{kg} / \mathrm{m}^{2}\right) \text {, mean } \\
\text { (SD) }\end{array}$ & $-1.58(2.24)$ & $-1.43(2.0)$ & $-2.05(2.67)$ & $-2.24(2.67)$ \\
\hline
\end{tabular}

Figure 5 illustrates the distribution of percentage weight change among the diabetes patients, where negative numbers indicate weight loss and positive numbers indicate weight gain.
The weight change of those individuals who have registered their parameters up to 180 days was $-3.9 \%$, for those up to 270 days was $-5.56 \%$, and for those up to 365 days was $-6.27 \%$ (Table 3). Figure 6 illustrates the weight change in kilos per person per day. 
Figure 5. Distribution of percentage weight change among the diabetes patients.

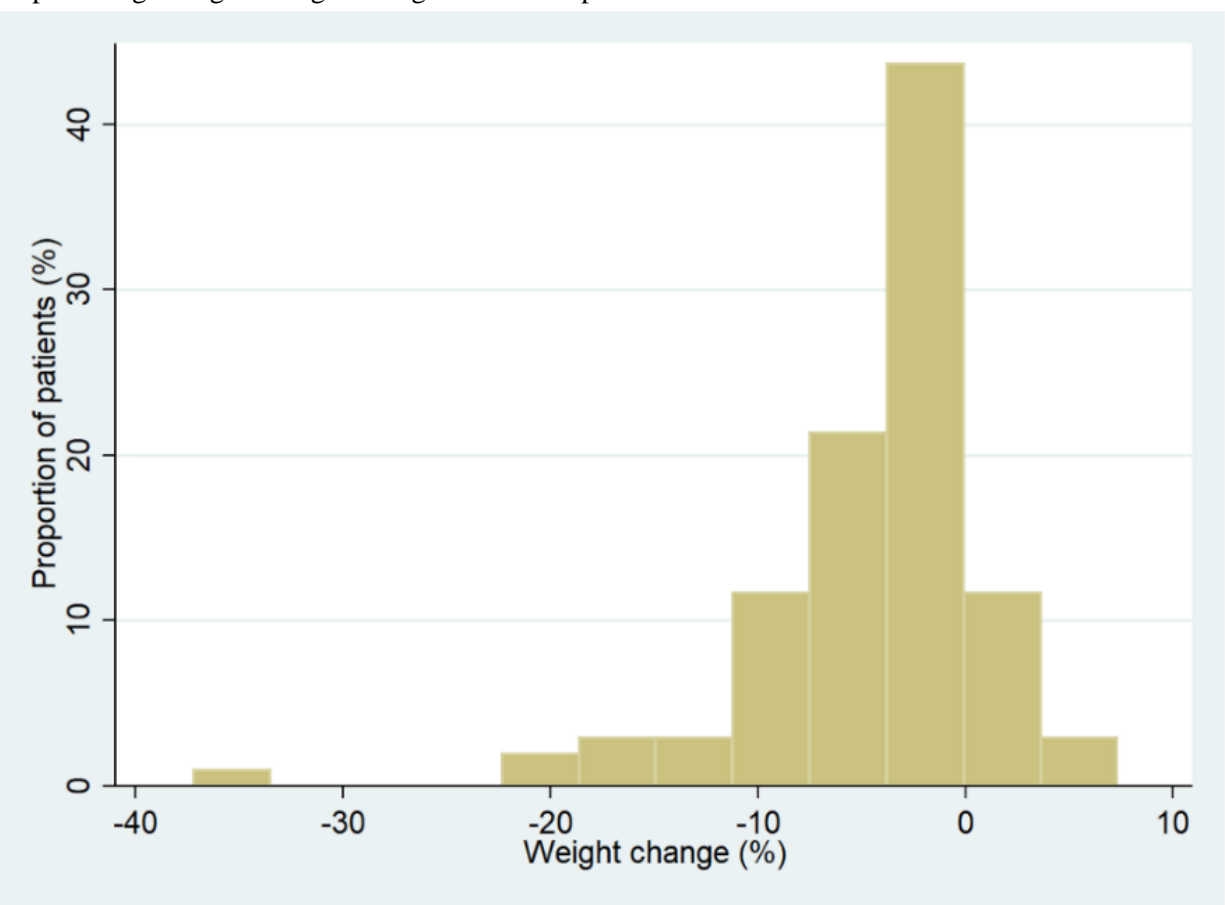

Figure 6. Weight change among the diabetes patients in intervention. Each dot represents a weight change estimated from the weight parameters registered by each diabetes patient. The red line with grey area illustrates prediction from a linear regression of weight change on days in intervention, including the CIs.

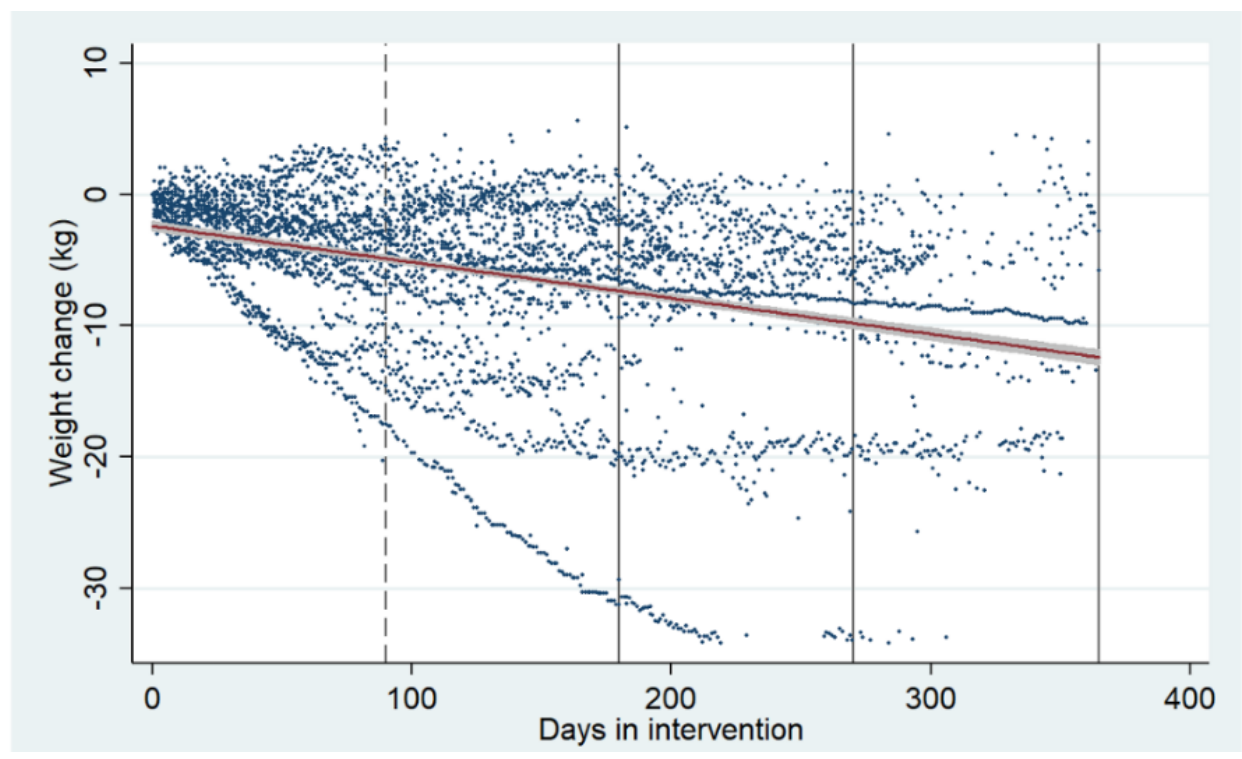

\section{Difference Between Patient Groups}

The mean weight change among male patients was $-5.04 \mathrm{~kg}$ and among female patients was $-4.56 \mathrm{~kg}$; the difference of 0.48 $\mathrm{kg}$ between the gender groups was not significant $(P=.72)$. The observed mean weight change among patients older than 40 years $(\mathrm{N}=9)$ was $-4.7 \mathrm{~kg}$, 40 years to 59 years $(\mathrm{N}=56)$ was $-4.9 \mathrm{~kg}$, and 60 years or older $(\mathrm{N}=38)$ was $-4.6 \mathrm{~kg}$. We applied 1-way ANOVA to examine mean weight change between the 3 age groups and found that the difference observed between the age groups was insignificant $(P=.99)$.

\section{Impact of Intervention on Weight Change}

The results of regression analysis indicate that participation in intervention has a significant impact on weight change, where time in intervention is associated with weight loss, implying that an extra day in intervention corresponds to $16 \mathrm{~g}$ weight loss $(P=.02)$ or about $480 \mathrm{~g}$ per month (Table 4$)$.

The additional explanatory variables were investigated with regard to the impact on weight change $(\mathrm{kg})$. Table 5 presents the outcomes of the linear regression, where number of forum posts and engagement rate $(\%)$ are associated with weight loss, but results are statistically insignificant $(P>.10)$. 
Table 4. Results from regression analyses for prediction of weight change ( $\mathrm{kg})$. Regression model summary: $\mathrm{N}=103 ; R^{2}=.108$; adjusted $R^{2}=.071$.

\begin{tabular}{lll}
\hline Explanatory variable & Regression coefficient & $P$ value \\
\hline Time & -0.016 & .02 \\
Baseline body mass index & -0.280 & .03 \\
Age & -0.008 & .90 \\
Gender & 0.519 & .69 \\
Constant & 8.503 & .29 \\
\hline
\end{tabular}

Table 5. Results from regression analyses for prediction of weight change ( $\mathrm{kg})$. Regression model summary: $\mathrm{N}=103 ; R^{2}=.120$; adjusted $R^{2}=.055$.

\begin{tabular}{lll}
\hline Explanatory variable & Regression coefficient & $P$ value \\
\hline Time & -0.013 & .03 \\
Baseline body mass index & -0.252 & .06 \\
Age & -0.018 & .78 \\
Gender & 1.079 & .43 \\
Sent messages & 0.017 & .69 \\
Forum posts & -0.131 & .29 \\
Engagement & -0.024 & .50 \\
Constant & 8.503 & .29 \\
\hline
\end{tabular}

\section{Discussion}

\section{Principal Findings}

Results show an average weight loss of $4.8 \mathrm{~kg}$ corresponding to $4.3 \%$ of initial body weight over a mean period of approximately 7 months. According to regression analysis, the weight loss is significant over time $(P<.05)$. We found that time spent in intervention was the main driver for weight loss. Gender and age did not significantly influence the outcomes, indicating that the intervention effect is not dependent on traditional demographic characteristics, as often anticipated in lifestyle interventions [21].

Despite the anticipated impact of engagement in the app along with forum activity and messaging frequency on weight loss, the insignificant results indicate that motivation within the intervention is not equal to activity and engagement in the digital device. Further research based on a larger sample size would improve the results.

Haste et al found an average weight loss of $5.4 \mathrm{~kg}$ for the ones who completed a 12-month Web-based weight loss intervention for men with type 2 diabetes in a previous Web-based version of the collaborative eHealth intervention in a pilot randomized controlled trial in a municipality setting [6]. Other eHealth coaching programs among diabetes patients have found weight reductions of $6.8 \%$ to $7.5 \%$ of body weight among completers after 6 to 12 months [22-24]. A review concluded a mean reduction in body weight of $3.73 \mathrm{~kg}$ after 12 months among 13 studies, analyzing the effect of BCTs on diet and physical activity in type 2 diabetes [25]. This indicates that the validity of the trends observed is promising, especially given the modest investment compared with traditional lifestyle change or exercise interventions.
This study evaluates the effects associated with a real-life eHealth lifestyle coaching intervention (LIVA) in 8 Danish municipalities. The observational design allows for data to reflect a real-life setting based on a substantial number of observations; results show clear tendencies of significant self-reported weight reduction among diabetes patients.

Within the scope of this study, we conducted an extensive review of available literature that observes the impacts of weight reduction among the obese diabetes patients on the costs of diabetes [26-31]. Following the literature review, we expect that a $1 \%$ reduction in weight among diabetes patients corresponds to $3.1 \%$ decrease in societal costs of diabetes in Denmark, which were previously estimated by Sorts $\varnothing$ et al [32]. The average weight loss of $4.3 \%$ among the diabetes patients within the cohort has a potential to reduce the annual diabetes costs of a single diabetes patient by $13.33 \%$, corresponding to Euro 2676 savings per diabetes patient per year, compared with the no-intervention scenario (the costs of intervention were not included). Subtracting the implementation and running costs of the intervention, the implementation was found to be cost-effective in a municipal perspective already after 1 year of implementation [33].

Preventive strategies within diabetes have gained ground the past decade, for example, the Diabetes Prevention Program in the United States [22,24,34]. The National Health Service also launched a National Diabetes Prevention Program (NDPP) in 2016, which covered 75\% of the nation in April 2017 [35,36]. These programs were initiated based on the expectation that lifestyle change among people at risk of or early in their diabetes will be effective in reducing the incidence of diabetes as well as late complications, thereby reducing costs. The economic assessment of the NDPP is undertaken from a 20-year perspective because of the disease structure of diabetes with 
risk of complications, and hence costs, increasing over time [37].

\section{Limitations of the Study}

Self-reported data are always subject for reporting bias. Other studies have, however, shown that self-reported data in Web-based eHealth solutions are valid [38]. As we observe a weight difference as our outcome, we assume reporting bias to be equal for both baseline and end data. An objective measurement and improved registration of comorbidities could strengthen the data and allow the distribution of diabetes patients across complication groups.

This study reflects a natural experiment in the sense that we observe a running program implemented in a real-life municipal setting. This is a strength as well as a limitation in relation to disentangling the effect of the program. In a longer follow-up, analysis with more observations within municipalities would provide valuable insights.

Long-term evidence on sustainability of results is needed within this area. Hence, a register-based study with observation of actual costs of participants over a longer follow-up period and subsequent comparison with control population would provide important new knowledge. Furthermore, as we observe different effects of the program across municipalities, there is a need for in-depth analysis within each municipality to investigate what is decisive for the effect.

\section{Conclusions}

We found that the collaborative eHealth tool significantly reduced weight among diabetes patients, on average $4.3 \%$ of the initial body mass with potential substantial cost savings. This study is based on a study population consisting of 103 individuals with diabetes, and it brings forward evidence of a positive effect of a running municipal secondary preventive offer that targets diabetes patients. Our study establishes a framework for further evaluation of eHealth tools where new data from longer follow-up can be examined to strengthen conclusions from this study.

\section{Perspectives and Implications}

The findings in this study are of relevance for all HCPs working with primary and secondary prevention of diabetes. Collaborative eHealth lifestyle coaching tools offer promising new opportunities for successfully changing diabetes patients' lifestyles. However, much remains unknown in this new era of eHealth possibilities. The results presented in this study are of importance, stressing that with a relatively modest personal resource investment, a collaborative eHealth lifestyle coaching tool can enable tailored coaching, resulting in significant weight losses among diabetes patients. We believe that these preliminary results show promising tendencies; however, there is a way yet to demonstrate sustainability of the weight loss attained as well as specific cost savings. We will investigate these issues along with long-term data arriving.

\section{Acknowledgments}

The study is funded by LIVA Healthcare A/S, the University of Southern Denmark, and the Region for Southern Denmark.

\section{Conflicts of Interest}

The Institute of Applied Economics and Health Research Aps (ApHER) received a grant from LIVA Healthcare A/S to conduct the analysis. AK, ME, and CS were employed at ApHER. CJB owns stocks in LIVA Healthcare A/S, the company that developed parts of the technical platform and hosted some of it during the study. DH is employed by LIVA Healthcare A/S.

\section{References}

1. World Health Organization. 2017. Fact sheet: Noncommunicable diseases URL: http://www.who.int/en/news-room/ fact-sheets/detail/noncommunicable-diseases [accessed 2018-08-17] [WebCite Cache ID 71k5Wo6dr]

2. World Health Organization. 2014. Global status report on noncommunicable diseases 2014 URL: https://www.who.int/ nmh/publications/ncd-status-report-2014/en/ [accessed 2019-03-06] [WebCite Cache ID 76ftvLLzi]

3. Allen NE, Song J, Paul SS, Smith S, O'Duffy J, Schmidt M, et al. An interactive videogame for arm and hand exercise in people with Parkinson's disease: a randomized controlled trial. Parkinsonism Relat Disord 2017 Aug;41:66-72. [doi: 10.1016/j.parkreldis.2017.05.011] [Medline: 28528804]

4. Afshin A, Babalola D, Mclean M, Yu Z, Ma W, Chen C, et al. Information technology and lifestyle: a systematic evaluation of internet and mobile interventions for improving diet, physical activity, obesity, tobacco, and alcohol use. J Am Heart Assoc 2016 Aug 31;5(9) [FREE Full text] [doi: 10.1161/JAHA.115.003058] [Medline: 27581172]

5. Levine DM, Savarimuthu S, Squires A, Nicholson J, Jay M. Technology-assisted weight loss interventions in primary care: a systematic review. J Gen Intern Med 2015 Jan;30(1):107-117. [doi: 10.1007/s11606-014-2987-6] [Medline: 25134692]

6. Haste A, Adamson AJ, McColl E, Araujo-Soares V, Bell R. Web-based weight loss intervention for men with type 2 diabetes: pilot randomized controlled trial. JMIR Diabetes 2017 Jul 07;2(2):e14 [FREE Full text] [doi: 10.2196/diabetes.7430] [Medline: 30291100]

7. Limaye T, Kumaran K, Joglekar C, Bhat D, Kulkarni R, Nanivadekar A, et al. Efficacy of a virtual assistance-based lifestyle intervention in reducing risk factors for type 2 diabetes in young employees in the information technology industry in India: LIMIT, a randomized controlled trial. Diabet Med 2017 Dec;34(4):563-568. [doi: 10.1111/dme.13258] [Medline: 27589695]

8. Block G, Azar KM, Romanelli RJ, Block TJ, Hopkins D, Carpenter HA, et al. Diabetes prevention and weight loss with a fully automated behavioral intervention by email, web, and mobile phone: a randomized controlled trial among persons 
with prediabetes. J Med Internet Res 2015 Oct 23;17(10):e240 [FREE Full text] [doi: 10.2196/jmir.4897] [Medline: 26499966]

9. Brandt V, Brandt CJ, Glintborg D, Arendal C, Toubro S, Brandt K. Sustained weight loss during 20 months using a personalized interactive internet based dietician advice program in a general practice setting. International Journal on Advances in Life Sciences Internet 2011;3(1 \& 2):23-28 [FREE Full text]

10. Koch C, From K, Beck R, Sode A, Brandt CJ, Bolting L, et al. Liva Healthcare. URL: https://livahealthcare.com/about/ [accessed 2019-02-15] [WebCite Cache ID 76Ck50aG6]

11. Brandt CJ, Søgaard GI, Clemensen J, Sndergaard J, Nielsen JB. General practitioners' perspective on eHealth and lifestyle change: qualitative interview study. JMIR Mhealth Uhealth 2018 Apr 17;6(4):e88 [FREE Full text] [doi: 10.2196/mhealth.8988] [Medline: 29666045]

12. Brandt CJ, Clemensen J, Nielsen JB, Søndergaard J. Drivers for successful long-term lifestyle change, the role of e-health: a qualitative interview study. BMJ Open 2018 Dec 12;8(3):e017466 [FREE Full text] [doi: 10.1136/bmjopen-2017-017466] [Medline: 29530904]

13. Ried-Larsen M, Christensen R, Hansen KB, Johansen MY, Pedersen M, Zacho M, et al. Head-to-head comparison of intensive lifestyle intervention (U-TURN) versus conventional multifactorial care in patients with type 2 diabetes: protocol and rationale for an assessor-blinded, parallel group and randomised trial. BMJ Open 2015 Dec 09;5(12):e009764 [FREE Full text] [doi: 10.1136/bmjopen-2015-009764] [Medline: 26656025]

14. Johansen MY, MacDonald CS, Hansen KB, Karstoft K, Christensen R, Pedersen M, et al. Effect of an intensive lifestyle intervention on glycemic control in patients with type 2 diabetes: a randomized clinical trial. J Am Med Assoc 2017 Dec 15;318(7):637-646. [doi: 10.1001/jama.2017.10169] [Medline: 28810024]

15. Diabetes Prevention Program (DPP) Research Group, Hamman RF, Horton E, Barrett-Connor E, Bray GA, Christophi CA, et al. Factors affecting the decline in incidence of diabetes in the Diabetes Prevention Program Outcomes Study (DPPOS). Diabetes 2015 Mar;64(3):989-998 [FRE Full text] [doi: 10.2337/db14-0333] [Medline: 25277389]

16. Brandt CJ, Søgaard GI, Clemensen J, Søndergaard J, Nielsen JB. Determinants of successful eHealth coaching for consumer lifestyle changes: qualitative interview study among health care professionals. J Med Internet Res 2018 Jul 05;20(7):e237. [doi: 10.2196/jmir.9791] [Medline: 29980496]

17. Brandt CJ, Brandt V, Pedersen M, Glintborg D, Toubro S, Nielsen JB, et al. Long-term effect of interactive online dietician weight loss advice in general practice (LIVA) protocol for a randomized controlled trial. Int J Family Med 2014;2014:245347 [FREE Full text] [doi: 10.1155/2014/245347] [Medline: 24860666]

18. Sherrington A, Newham JJ, Bell R, Adamson A, McColl E, Araujo-Soares V. Systematic review and meta-analysis of internet-delivered interventions providing personalized feedback for weight loss in overweight and obese adults. Obes Rev 2016 Jun;17(6):541-551 [FREE Full text] [doi: 10.1111/obr.12396] [Medline: 26948257]

19. Hoffmann TC, Glasziou PP, Boutron I, Milne R, Perera R, Moher D, et al. Better reporting of interventions: template for intervention description and replication (TIDieR) checklist and guide. Br Med J 2014;348:g1687 [FREE Full text] [Medline: 24609605]

20. Michie S, Ashford S, Sniehotta FF, Dombrowski SU, Bishop A, French DP. A refined taxonomy of behaviour change techniques to help people change their physical activity and healthy eating behaviours: the CALO-RE taxonomy. Psychol Health 2011 Nov;26(11):1479-1498. [doi: 10.1080/08870446.2010.540664] [Medline: 21678185]

21. Crane MM, Jeffery RW, Sherwood NE. Exploring gender differences in a randomized trial of weight loss maintenance. Am J Mens Health 2017 Dec;11(2):369-375 [FREE Full text] [doi: 10.1177/1557988316681221] [Medline: 27923968]

22. Chen F, Su W, Becker SH, Payne M, Castro SC, Peters AL, et al. Clinical and economic impact of a digital, remotely-delivered intensive behavioral counseling program on medicare beneficiaries at risk for diabetes and cardiovascular disease. PLoS One 2016;11(10):e0163627 [FREE Full text] [doi: 10.1371/journal.pone.0163627] [Medline: 27706216]

23. Castro SC, Chiguluri V, Gumpina R, Abbott P, Madero EN, Payne M, et al. Outcomes of a digital health program with human coaching for diabetes risk reduction in a medicare population. J Aging Health 2017 Jan 01;30(5):898264316688791. [doi: 10.1177/0898264316688791] [Medline: 28553807]

24. Michaelides A, Raby C, Wood M, Farr K, Toro-Ramos T. Weight loss efficacy of a novel mobile Diabetes Prevention Program delivery platform with human coaching. BMJ Open Diabetes Res Care 2016;4(1):e000264 [FREE Full text] [doi: 10.1136/bmjdrc-2016-000264] [Medline: 27651911]

25. Cradock KA, ÓLaighin G, Finucane FM, Gainforth HL, Quinlan LR, Ginis KA. Behaviour change techniques targeting both diet and physical activity in type 2 diabetes: a systematic review and meta-analysis. Int J Behav Nutr Phys Act 2017 Feb 08;14(1):18 [FREE Full text] [doi: 10.1186/s12966-016-0436-0] [Medline: 28178985]

26. Yu AP, Wu EQ, Birnbaum HG, Emani S, Fay M, Pohl G, et al. Short-term economic impact of body weight change among patients with type 2 diabetes treated with antidiabetic agents: analysis using claims, laboratory, and medical record data. Curr Med Res Opin 2007 Sep;23(9):2157-2169. [doi: 10.1185/0300799007X219544] [Medline: 17669232]

27. Bell K, Parasuraman S, Shah M, Raju A, Graham J, Lamerato L, et al. Economic implications of weight change in patients with type 2 diabetes mellitus. Am J Manag Care 2014 Aug 01;20(8):e320-e329 [FREE Full text] [Medline: 25295795] 
28. Mukherjee J, Sternhufvud C, Smith N, Bell K, Stott-Miller M, McMorrow D, et al. Association between weight change, clinical outcomes, and health care costs in patients with type 2 diabetes. J Manag Care Spec Pharm 2016 May;22(5):449-466 [FREE Full text] [doi: 10.18553/jmcp.2016.22.5.449] [Medline: 27123909]

29. Nichols GA, Bell K, Kimes TM, O'Keeffe-Rosetti M. Medical care costs associated with long-term weight maintenance versus weight gain among patients with type 2 diabetes. Diabetes Care 2016 Dec;39(11):1981-1986. [doi: 10.2337/dc16-0933] [Medline: 27561921]

30. Davis WA, Bruce DG, Davis TME. Economic impact of moderate weight loss in patients with type 2 diabetes: the Fremantle Diabetes Study. Diabet Med 2011 Sep;28(9):1131-1135. [doi: 10.1111/j.1464-5491.2011.03314.x] [Medline: 21843308]

31. Dilla T, Valladares A, Nicolay C, Salvador J, Reviriego J, Costi M. Healthcare costs associated with change in body mass index in patients with type 2 diabetes mellitus in Spain: the ECOBIM study. Appl Health Econ Health Policy 2012 Nov 1;10(6):417-430 [FREE Full text] [doi: 10.2165/11634030-000000000-00000] [Medline: 23013427]

32. Sorts $\varnothing$ C, Green A, Jensen P, Emneus M. Societal costs of diabetes mellitus in Denmark. Diabet Med 2016 Dec;33(7):877-885 [FREE Full text] [doi: 10.1111/dme.12965] [Medline: 26414087]

33. Institute of Applied Economics and Health Research. 2017. LIVA Healthcare 2017 Cost-Effectiveness Analysis URL: https://livahealthcare.com/wp-content/uploads/2018/11/Report Apehr 2017.pdf [accessed 2018-12-03] [WebCite Cache ID 7409kQzOl]

34. National Institute of Diabetes and Digestive and Kidney Diseases (NIDDK). 2008. The Diabetes Prevention Program (DPP) URL: https://www.niddk.nih.gov/-/media/Files/Research-Areas/DPP 508.pdf

35. NHS England. 2017. NHS Diabetes Prevention Programme (NHS DPP) URL: https://www.england.nhs.uk/diabetes/ diabetes-prevention/ [accessed 2018-08-17] [WebCite Cache ID 71k7EjEB9]

36. NHS England. 2016. NHS England Impact Analysis of implementing NHS Diabetes Prevention Programme, 2016 to 2021 URL: https://www.england.nhs.uk/publication/ nhs-england-impact-analysis-of-implementing-nhs-diabetes-prevention-programme-2016-to-2021/ [accessed 2018-08-17] [WebCite Cache ID 71k8JoNDw]

37. Briggs A, Claxton K, Sculpher M. Decision Modelling For Health Economic Evaluation (Handbooks In Health Economic Evaluation). New York: Oxford University Press; 2006.

38. Burke LE, Wang J, Sevick MA. Self-monitoring in weight loss: a systematic review of the literature. J Am Diet Assoc 2011 Jan;111(1):92-102 [FREE Full text] [doi: 10.1016/j.jada.2010.10.008] [Medline: 21185970]

\author{
Abbreviations \\ ANOVA: analysis of variance \\ ApHER: Institute of Applied Economics and Health Research Aps \\ BCT: behavior change technique \\ BMI: body mass index \\ eHealth: electronic health \\ HCP: health care professional
}

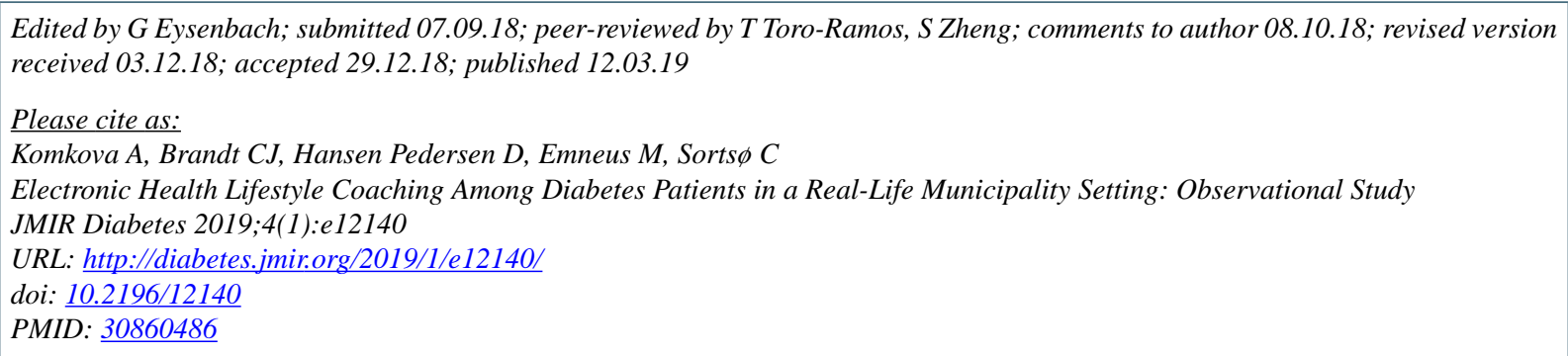

(C)Anastasija Komkova, Carl Joakim Brandt, Daniel Hansen Pedersen, Martha Emneus, Camilla Sortsø. Originally published in JMIR Diabetes (http://diabetes.jmir.org), 12.03.2019. This is an open-access article distributed under the terms of the Creative Commons Attribution License (https://creativecommons.org/licenses/by/4.0/), which permits unrestricted use, distribution, and reproduction in any medium, provided the original work, first published in JMIR Diabetes, is properly cited. The complete bibliographic information, a link to the original publication on http://diabetes.jmir.org/, as well as this copyright and license information must be included. 